Article

\title{
Primary Frequency Response Enhancement for Future Low Inertia Power Systems Using Hybrid Control Technique
}

\author{
Abdulhameed S. Alsharafi ${ }^{1}$, Ahmad H. Besheer ${ }^{2,3, *}$ and Hassan M. Emara ${ }^{1}$ \\ 1 Electrical Power and Machines Department, Cairo University, Giza 12613, Egypt; \\ alsharafi.ab@pg.cu.edu.eg (A.S.A.); hmrashad@gmail.com (H.M.E.) \\ 2 Environmental Studies and Research Institute, University of Sadat City, Sadat City 32897, Egypt \\ 3 Electrical Power Department, Higher Institute of Eng. \& Modern Technology Marge, Cairo 11721, Egypt \\ * Correspondence: ahmed.tawfeek@esri.usc.edu.eg; Tel.: +20-100-111-0744
}

Received: 4 March 2018; Accepted: 14 March 2018; Published: 21 March 2018

\begin{abstract}
Maintaining the stability of a conventional power system during under frequency events is partially dominated by a natural behavior called inertial response. Although a variable speed wind turbine (VSWT) is fundamentally deprived from such behavior, it was shown recently that it can virtually emulate this response, hence increasing its output power given to the grid to sustain the power balance. This paper reviews and analyzes the performance of four primary frequency control structures, and provides comparison between these controllers in terms of security indices. The results reflect the superiority of the inertia emulation controller and the droop control type in low and high wind speed respectively. To enhance the system frequency control response and take any inherent advantage of each controller, this paper proposes two novel controllers based on combination (hybridization) strategy between the four controllers. The results show that the combination between the inertia emulation controller and the de-loading controller will lead to reducing the rate of change of frequency (ROCOF) and raising the frequency nadir (FN) values. Finally, the role of each discussed controller in determining the correlations among ROCOF, FN and wind power penetration level are explored.
\end{abstract}

Keywords: primary frequency control; wind turbine; inertia control; frequency nadir

\section{Introduction}

The worldwide power system is shifting towards integrating more renewable energy generation technologies. The motivating factors behind this upward trend are the desire to increase the diversity and security of fuel supply, owing to the increase in fossil fuel costs, and the environmental concerns about conventional generators. Many countries have set global targets for decreasing the carbon dioxide $\left(\mathrm{CO}_{2}\right)$ and other greenhouse gas emissions via increasing the capacity of electricity generation from renewable energy sources [1]. At present, it is mentioned that wind is the most widely utilized and fastest growing renewable energy technology for generating electricity, with a total installed capacity of approximately $487 \mathrm{GW}$ worldwide at the end of 2016 [2].

The new trends in harnessing renewable resources such as wind energy create several challenges for future power systems. For instance, the increased utilization of switched mode high power converters to facilitate integrating wind turbines into the electric grid modifies the total system inertia and impacts the system's ability to overcome frequency excursion due to inevitable production consumption imbalance or frequency disturbance events due to fault conditions. Although this problem is particularly of interest for isolated and weak electric networks [3], it may also adversely affect large interconnected power systems with high wind power penetration and more halted 
conventional power plants (low inertia power system). This means that wind power generation systems are not inherently able to respond to any probable frequency deviations in the system. Consequently, and unlike conventional power plants, the output power from these generation systems will not directly respond to variations in system frequency. This motivates the research community to search for technical solutions to let variable speed wind turbines (VSWTs) contribute to the system inertia and to support primary frequency control. The importance of the frequency regulation needed for such kind of renewable energy technology is emphasized in many works (e.g., [4-7]).

Several control techniques are proposed in the literature to support the system frequency with increasing the penetration of the wind energy in the electric grid. Dreidy et al. [8] generally split these control methods into two categories. The first one is with energy storage system where the additional power comes primarily from different energy storage devices such as batteries, super capacitors, etc. The second one is without energy storage systems where inertial control concepts and demand response programs are playing vital rule in amending the frequency deviation. Sun et al. [9] introduced a review on the contribution of wind power for frequency control. It divided the frequency control problem into three levels of control that can be applied on the wind turbine level, wind farm level and power system level, where the wind turbine level includes inertial, droop and de-loading controllers as the primary control that are installed locally on the power electronic converters of VSWTs. This paper focuses on using the control method without energy storage and utilizing the concept of synthetic inertia to support the frequency. Figure 1 shows the general classification for different control strategies based on different working ideas and principles for inertia emulation concept.

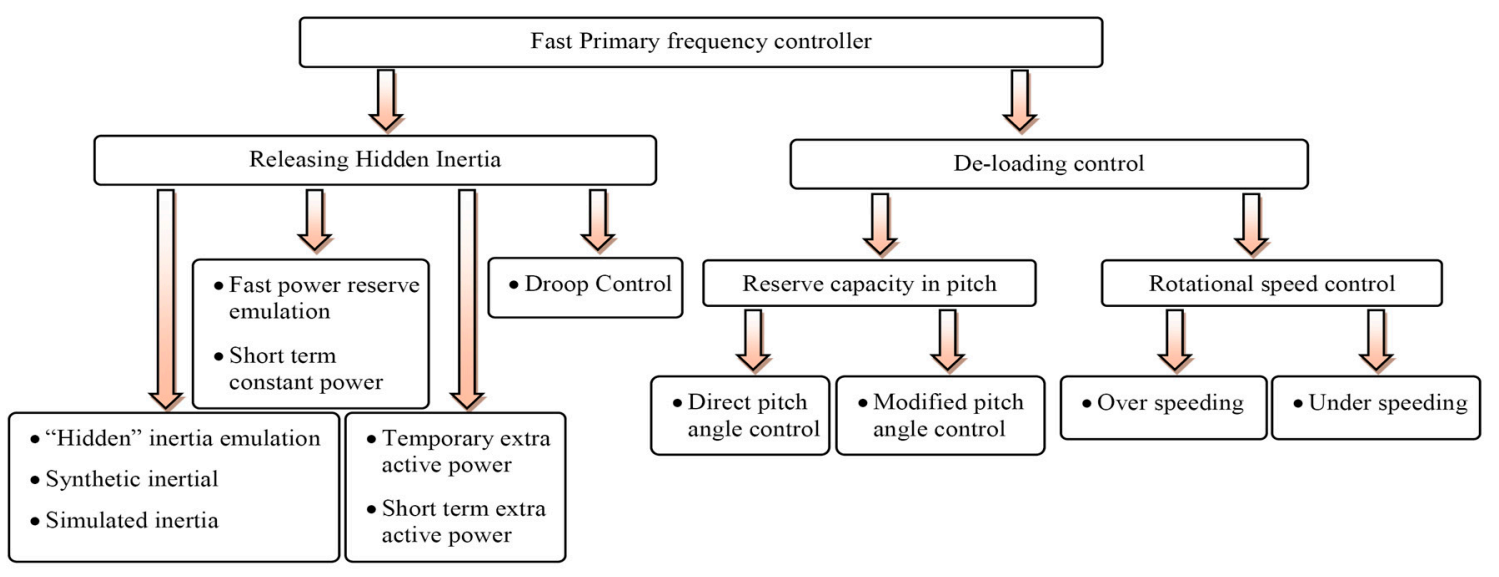

Figure 1. Classification of control strategies.

Morren et al. [10] propose two simple gain controllers to change the torque set point depending on the frequency deviation and the frequency rate of change to emulate the hidden inertia and to support primarily the frequency, respectively. The same solution approach is proposed by Morren et al. [11], where a constant gain proportional to emulating inertia manipulates the feedback frequency rate of change signal. The controller showed better results with respect to the power, mechanical and electrical stress on the turbine. Following exactly the same controller, Zeni et al. [12] discussed the problems related to the implementation of virtual inertia and investigated the possibility of making the value of the virtual inertia a controllable parameter. The paper identifies the maximum theoretical limit of what is called the virtual inertia factor.

The synthetic inertia controller, its impact on the total system inertia and transient response after a frequency event is explored in [13]. The paper showed an enhanced effect on the total system inertia for the system that integrates such controller. Gonzalez-Longatt [14] emphasized that this controller cannot totally avoid the operation of the under frequency load shedding protective scheme.

Under the same category of inertia response control, Gonzalez et al. [15] evaluated two different control techniques, namely synthetic inertia and fast power reserve emulation. The paper concluded 
that the synthetic inertia controller is more desirable in low inertia systems while the fast power reserve controller is desirable in high inertia system, considering that the deactivation time of the later controller may initiate a second system frequency disturbance (nadir). Many papers take the same direction and compared several controllers' performances in supporting the frequency. For instance, Yingcheng and Nengling [16] presented two wind turbine control methods (inertial and power reserve) that enable frequency control for VSWT and discussed the advantages and disadvantages of each method. Motamed et al. [17] compared three primary frequency controllers, namely, short-term extra active power, inertia emulation and direct pitch angle regulation. The paper identified the best separate and combined controller in terms of temporary minimum frequency (TMF). The paper also expressed the favor of utilizing the direct pitch angle control in the two forms.

In this work, four primary response based control structures to support the grid frequency in hydro dominated wind energy environment by mimicking the inherent natural behavior of fast primary frequency response in conventional power plants are studied. The control performance of each studied controller is compared. The combinations of the four controllers are also evaluated. Two performance indices, namely rate of change of frequency (ROCOF) and frequency nadir (FN), are considered. These performance indices reflect the effect of high penetration of VSWT in the grid under different primary frequency controls.

The main contribution of this paper is that it proposes novel controller structures by combining two established concepts, namely "releasing the hidden inertia" and "reserve capacity in pitch", to primarily regulate the system frequency despite the production/consumption imbalance. The primary advantages of this work are as follows:

- The proposed controller equips the VSWT with a sufficient ability to play an active role in responding to unforeseen grid transients.

- The proposed controller extends the results found in the literature by not only arresting the frequency excursion, hence maintaining the system stability, but also enhancing the system security indices, namely ROCOF and FN.

- $\quad$ All the proposed controller combinations succeed in providing extra generation capacity (i.e., reserve) to balance the mismatch in the generation demand requirements.

- The controllers cure the main shortcoming of using converter by eliminating its decoupling effect between the VSWT and the grid.

The paper is organized as follows. Section 1 gives a generic introduction about the problem under studies. Section 2 provides the necessary preliminaries where the frequency response in conventional Power system is firstly introduced. Then, the studied mathematical model of the wind turbine hydro dominated electric grid is presented. Section 3 addresses the main concepts behind the chosen control philosophies applied in this paper. Sections 4 and 5 show the control performance simulation verifications under different wind speed operating conditions and discusses its results. A new combination strategy for the simulated controllers is established and analyzed as well. Section 6 discusses the effect of high wind power penetration on the system frequency and other security indices for each studied controller. Finally, the conclusions is drawn in Section 7.

\section{Preliminary}

In the following subsections, the frequency response in conventional power system is discussed. Then, the wind turbine hydro dominated power system model used in this paper is presented.

\subsection{Frequency Response in Conventional Power System}

To ensure the service continuity of any power system, its frequency should be within a permissible range of its nominal value $(50 \mathrm{or} 60 \mathrm{~Hz}$ ) which may be affected by the active power balance between the generation and the demand. 
Normal standard requires the frequency excursion of $\pm 0.2 \mathrm{~Hz}$ under regular operating states. This excursion could be raised to $\pm 0.5 \mathrm{~Hz}$ if the total grid capacity is not high. If there is a large frequency disturbance, the power system requires a frequency control (primary and secondary) to correct the frequency disturbance $[13,18]$. Figure 2 describes the overall system frequency response with emphasizing on the effect of the total inertia of the power system in Great Britain [19]. It is clear that the frequency response passes through two main states. The first one is called primary response with a time frame range from $0 \mathrm{~s}$ to $30 \mathrm{~s}$, which can be further split into two distinct zones that represent fast primary response from $0 \mathrm{~s}$ to $10 \mathrm{~s}$ and slow primary response from $10 \mathrm{~s}$ up to $30 \mathrm{~s}$. The second one is called secondary response with a range of several up to thirty minutes. Other additional and slower frequency control (tertiary control is not shown in the figure.

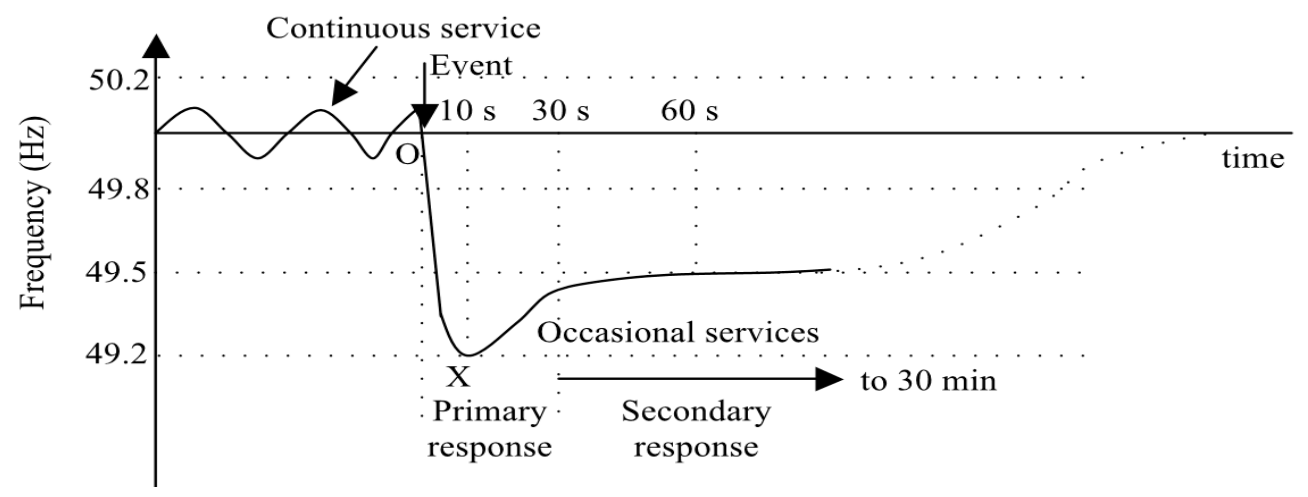

Figure 2. General system frequency response.

Generally speaking, the high penetration of wind power source in any electric grid results in frequency stability challenges, owing to the power electronics converter that decouples the wind turbine from the power system. Thus, the power system will be deprived from the inertia response that could be given by the VSWTs. In such cases, a control technique is needed to support and regulate the frequency [8]. Figure 3 shows the impact of increasing the penetration level of wind turbine in the electric grid. The figure reflects the need for proposing solution to alleviate the increase in the frequency deviation in the case of high wind penetration level.

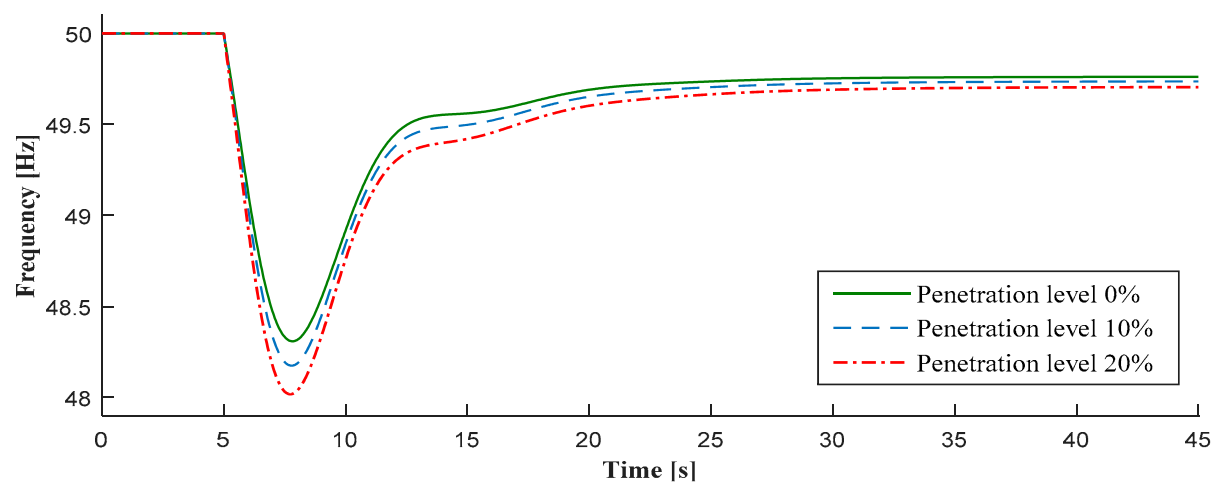

Figure 3. Frequency response with different wind power penetration level without frequency control.

\subsection{Frequency Response in Conventional Power System}

Basically, the wind turbine inertia can be defined based on the amount of stored kinetic energy in the wind turbine rotating blades. The stored kinetic energy and the inertia constant are defined as Equations (1) and (2):

$$
E=\frac{1}{2} J \omega^{2}
$$




$$
H=\frac{\frac{1}{2} J \omega^{2}}{s}
$$

where $\omega$ is the turbine rotor rotational speed, $J$ is its moment of inertia, $S$ is the nominal value of the apparent power and $H$ is the inertia constant measured in seconds. Morren et al. [10] stated the typical values of this constant to be about $2-6 s$ and emphasized that wind turbine hidden capability to either emulate the inertia or support the grid frequency primarily can be released using additional control loops. The system used in this study represents micro grid comprised of hydro power station in addition to wind farm based on six-pitch regulated VSWT. This system is built and simulated in the MATLAB/Simulink (R2012b, MathWorks, Natick, MA, USA) environment.

The feedback control system for the studied model consists of three main building blocks. The first one is a hydro turbine model block. The second one is the governor with rotor/load model block to represent the power system [20]. The third model block is the wind farm which is mainly based on 3.6 MW commercial VSWT [21]. Figure 4 shows the general layout of the used model.

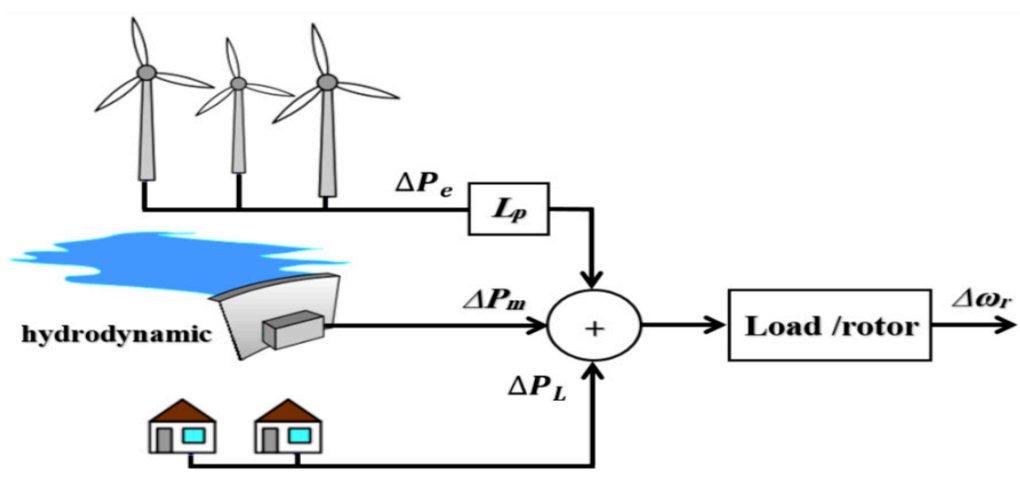

Figure 4. Wind turbines connected to hydro dominant power system.

For the wind turbine model block, $\Delta P_{e}$ expresses the change in measured electrical power, and $L_{P}$ is the level of the penetration of the wind turbine generators. For the hydrodynamic model block, $\Delta P_{m}$ is the change in the mechanical power, $\Delta \omega_{r}$ is the rotor speed deviation and $\Delta P_{L}$ is the change in the load demand. For the rotor/load model block, $H_{e q}$ is system inertia constant and $D$ is the load damping. It is worth mentioning here that the pitch control model is also included in the wind turbine model to secure both generator and turbine operations in above rated and under high wind speed conditions. Different gain values and limitations parameters for this model are found in [17]. Moreover, the following assumptions are considered:

- $\quad$ The contribution of the wind turbines in the system frequency changes is null.

- The wind penetration level $\left(L_{p}\right)$ affects the governor, the generator models and the total system inertia.

- Spinning reserve is available to compensate for any existing generating units in the case of any generation deficit.

\section{Methods for VSWT Primary Frequency Control}

In this section, four controllers types based on only the inertial control concept including the de-loading control technique are presented. These controllers can simply be realized as an additional control loop in the power electronics converter of the turbine. The controllers' main principles and related control (technique) strategies are analyzed. The proportional integral (PI) type controller is used in the most of the presented control techniques. The controlled (output) variables used are mainly: the system frequency, the frequency deviation, the rotor speed and the three-phase output current of the turbine generator. The control (manipulated) variables are incremental power or torque signal. 


\subsection{Use Kinetic Energy}

The main idea of this concept is to enable increasing the output power of the wind turbine for a few seconds to capture the frequency excursions in the case of frequency event. This power is principally released from the stored kinetic energy in the turbine blades rotation. This controller is imbedded in the switched mode power converter that is used essentially to enable the wind turbine working in the variable speed mode. The controller is activated once the deviation in the frequency becomes more than $20 \mathrm{mHz}$; this value can be adjusted according to the different grid codes. Hence, the reference power offered to the converter will change its value that will lead to change in the rotor speed (i.e., change in the kinetic energy of the rotor blades). This process will be associated with power released or absorbed from the power system which is known as the inertial response [18]. In this way, the wind turbine will be equipped with a new added functionality to work as the conventional power plant that inherently has inertial response due to the direct coupling between its synchronous generator and the AC grid. The inertial controller is implemented by the following two methods.

\subsection{1. "Hidden" Inertia Emulation}

This controller is a simple control loop added on the power converter controller [10] that creates an active power control signal (inertial power $P_{\text {in }}$ ) given by:

$$
P_{\text {in }}=2 H f_{\text {sys }} \frac{d f_{\text {sys }}}{d t}
$$

where $H$ is inertia constant and $f_{s y s}$ is the frequency of the system (per unit). Figure 5 shows the diagram of releasing "hidden" emulation inertia controllers. A low pass filter is added in the feed forward path with the derivative term to avoid any frequency noisy measurement [19].

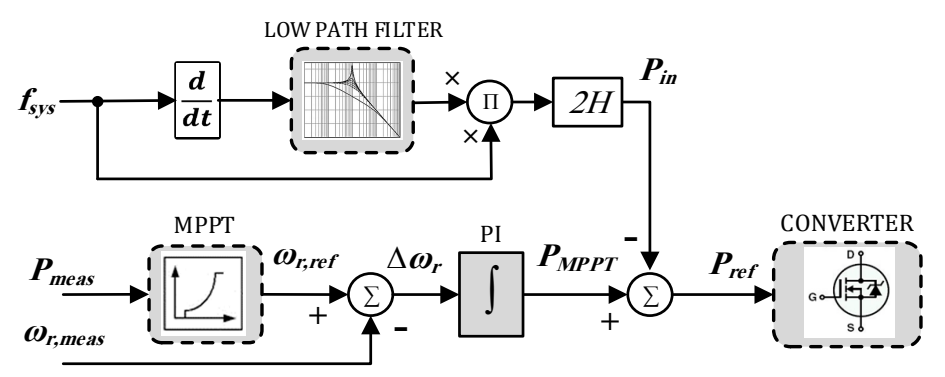

Figure 5. Releasing hidden inertia controller.

A normal maximum power point tracking (MPPT) block is also employed, which is only a static $P-\omega$ characteristic used to provide a reference speed for a definite power. The error signal between the measured and the reference speed is sent to a PI controller which is working in minimizing or attenuating this signal. The output control action from the PI controller represents the maximum power that should be followed by the converter in the normal condition and that is modified by $P_{\text {in }}$ (Equation (3)) in the case of frequency event [11].

\subsubsection{Fast Power Reserve Emulation}

The fast power reserve emulation controller is used to provide short term constant power and support the frequency response for a short period of time (e.g., $10 \mathrm{~s})$. The fast power reserve $\left(P_{\text {res }}\right)$ is derived from a simple integration of kinetic energy stored in the wind turbine rotor $[22,23]$ :

$$
P_{r e s} t=\frac{1}{2} J\left(\omega_{r, 0}^{2}-\omega_{r, t}^{2}\right)
$$


where $t<t_{\max }$ is the lasting time of the fast power reserve from the beginning of the frequency disturbance, $\omega_{r, 0}$ is the initial rotational speed and $\omega_{r, t}$ is the rotor rotational speed corresponding to $t$. Figure 6 shows the fast power reserve emulation controller scheme, where the new reference rotational speed $\left(\omega_{r, r e f}\right)$ is given as:

$$
\omega_{r, r e f}=\omega_{r, t}=\sqrt{\omega_{r, 0}^{2}-\frac{2 P_{r e s} t}{J}}
$$

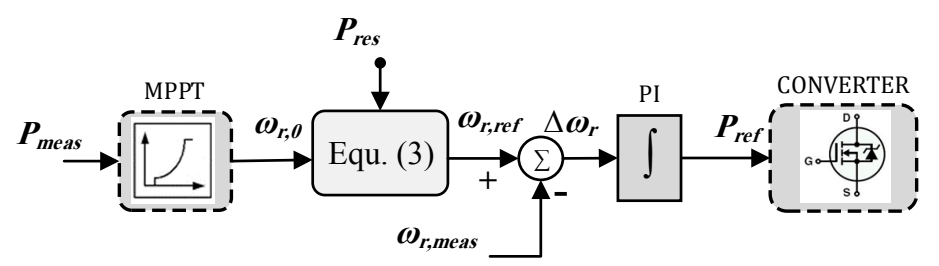

Figure 6. Fast power reserve emulation controller.

\subsection{Droop Control}

In $[8,24]$, a very simple structure of a proportional controller based on the difference between the grid frequency and its nominal value is proposed. This controller is similar to the droop controller in the conventional synchronous generators, which is normally used for supporting primary frequency control. The droop characteristic of the frequency is normally as depicted in Figure 7, where the change in the active power is directly proportion to the change in the frequency. The frequency and the active power changes are based on Equations (6) and (7). This controller will be activated once the frequency deviation increases certain threshold value, as specified in the grid code.

$$
\begin{gathered}
\Delta f=f_{g}-f_{m} \\
\Delta P=P_{g}-P_{m}=-\frac{\Delta f}{R}
\end{gathered}
$$

where $f_{g}$ is the real grid frequency, $f_{m}$ is the nominal reference frequency, $P_{g}$ is the active power at $f_{g}$, $P_{m}$ is the active power at $f_{m}$ and $R$ is the speed adjustment rate which also expresses the generator stiffness. A supplementary power signal will be generated as in Equation (8) and added to the power signal from MPPT controller, as shown in Figure $8 . K_{p}$ is the permanent droop.

$$
\Delta P=K_{p}(\Delta f)
$$

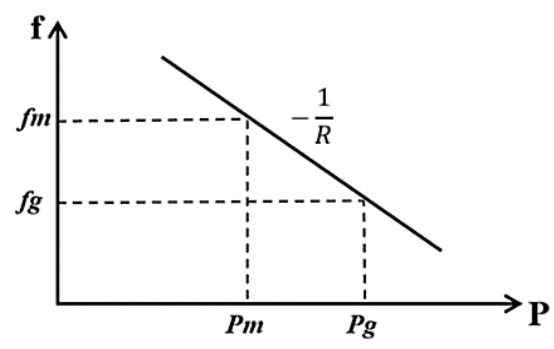

Figure 7. The droop Characteristics of the frequency. 


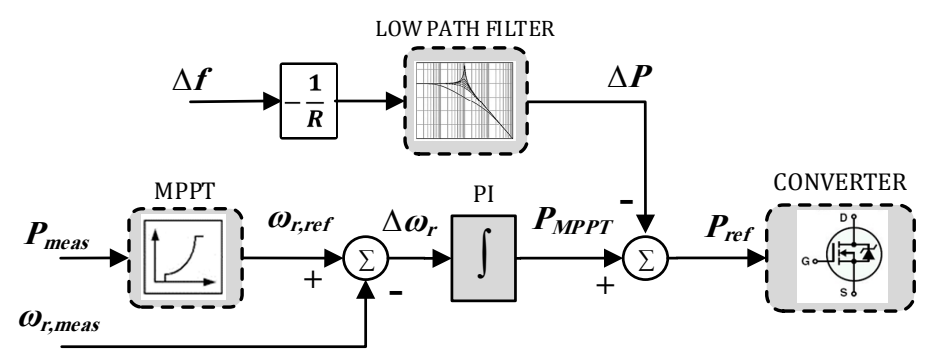

Figure 8. Droop control for VSWTs.

This increase in active power will be obtained from the kinetic energy store in the wind turbine blades making the rotor speed to drop with probability of stalling wind turbine under low operational rotational speed. This shortcoming may be avoided if a certain working time for this controller is specified similar to the case of fast power reserve emulation. In such case, a triggering system takes the rule to cut the droop control action on this prescribed time.

\section{Remark 1}

Comparing the above mention three control structures shown in Figures 5, 6 and 8 reflects the following points:

1. They all depend on the MPPT control block to determine the reference rotor speed of the wind turbine which may either be further corrected by the aid of PI controller to determine the normal reference maximum power signal as in the case of inertia emulation and droop control. In such cases, this MPPT signal is forwardly modified by an extra active power signal that can be produced from the stored kinetic energy in the turbine blades (hidden/synthetic/emulated inertia) or from speed adjustment rate constant $(R)$ as $\Delta f / \Delta P$ droop characteristics to produce the needed reference power signal for the converter hence reducing the frequency excursion.

2. Conversely, it may be used as an initial speed value in Equation (3), in addition to determining a short term constant power called Pin for certain specified period of time, $t$. In such case, the needed reference rotor speed of the wind turbine will be determined and compared with the measured value of the rotor speed to produce the needed reference power signal—by the aid of PI controller-for the converter hence reducing the frequency excursion.

\subsection{De-Loading Control}

Another control method used for primary frequency support and principally differs than the concepts of releasing hidden inertia and droop control shown in Section 2 is known as de-loading control. The main idea of this method is to scarify the MPPT operation and keep the power available as reserves. In such case, the wind turbine will no longer work over the MPPT curve but it works on de-loading curve. Figure 9 shows three de-loading possibilities known as over-speeding, under-speeding and pitching, which can be applied in low and high wind speed, respectively.

When the wind speed is below the rated value of wind speed, VSWT is always on the MPPT operation mode with the constant blade pitch angle $\left(\beta=\beta_{\min }=0\right)$. This operation mode allows exploiting the maximum power from the rotor speed of wind turbine as much as possible. If the wind speed is high enough to exceed the rated value, the pitch angle increases to maintain the rated output power [19].

The de-loading control can be realized by two ways: rotational speed control (either under- or over-speeding) in low wind speed case and pitch control in high wind speed case. Both methods will be discussed in the next sections. 


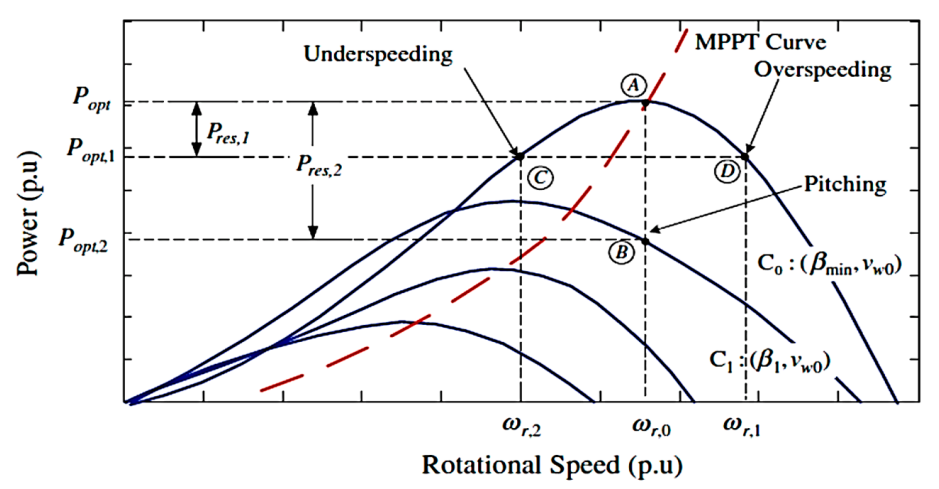

Figure 9. Different de-loading options and maximum power tracking curve.

\subsubsection{Rotational Speed Control}

This control is known as under/over-speeding action which has many advantages. It provides sufficient reserves for the system and saves investment on the storages by directly managing the energy in the wind which may be otherwise partially lost if the changes on the wind turbine speed cause stall [19]. Figure 10 shows a traditional rotational speed controller for a VSWT. In this controller, some sort of coordination with droop controller and other control parameters is needed.

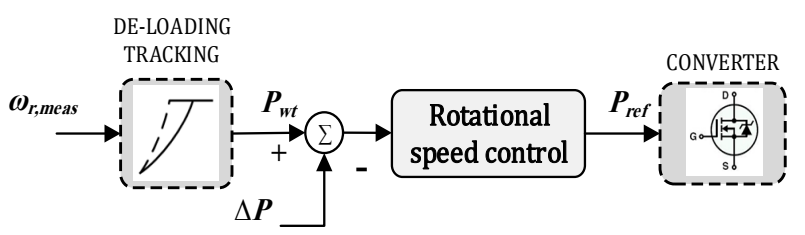

Figure 10. Rotational speed control.

\subsubsection{Modified Pitch Control}

Generally, the pitch control is a common technique which is used to regulate (increase/ decrease) the output power of the wind turbine generator and keep minimum fatigue loads of the turbine. This control technique can contribute in supporting the frequency response and give adequate power reserve without spending on storage technology. This can be performed using the simple modification shown in Figure 11 where the required modified pitch angle no longer depends on a rotor speed input signal but instead relies on a power difference signal between the current measured value of the power and the de-loading power value. This signal constitutes the actuating signal for a proportional integral controller used in traditional pitch angle control to obtain the modified pitch angle. In such kind of control, a hierarchical control approach is needed to coordinate with droop controller and other control parameters for successful implementation $[19,25]$.

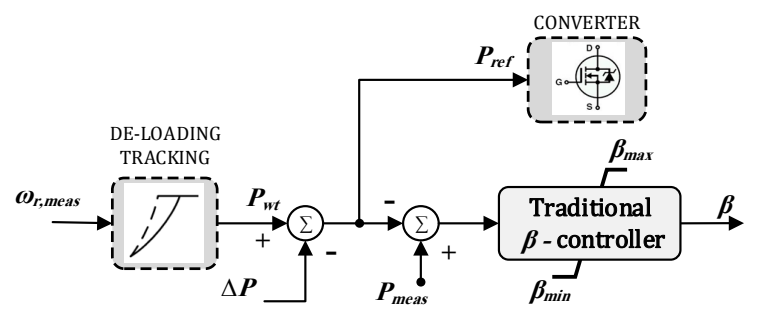

Figure 11. Modified pitch control. 


\section{Frequency Control Simulation}

In this section, MATLAB/Simulink simulation environment is utilized to validate each proposed controller in Section 2. The dynamic frequency response of wind power plant integrated with multi-machine hydro dominated power system is studied under the following environmental conditions:

- Condition 1: low wind speed.

- Condition 2: high wind speed.

Ten percent increase at the load side is applied after $5 \mathrm{~s}$ to represent a frequency event. According to the chosen wind turbine model [21], the wind speed is assumed to be $7.5 \mathrm{~m} / \mathrm{s}$ for the low-speed value and $20 \mathrm{~m} / \mathrm{s}$ for the high-speed value. The penetration level of the wind power in the proposed power system configuration is initially set to be $20 \%$. The simulation mainly focuses on studying the system frequency, the electrical power output given by the wind turbine and the wind turbine rotor speed variables with and without control. Four different control schemes are initially tested. As a step towards achieving better frequency response, a combination strategy is then suggested. This combination strategy is based on the combination matrix shown in Table 1.

Table 1. Combination strategy.

\begin{tabular}{cccc}
\hline & & \multicolumn{2}{c}{ Kinetic Energy } \\
\cline { 3 - 4 } & & Inertia Emulation & Fast Power Reserve Emulation \\
\hline \multirow{2}{*}{ De-loading } & Rotational speed & Low wind & Low wind \\
& Modified pitch & High wind & High wind \\
\hline
\end{tabular}

Furthermore, an analysis for the system security indices in terms of ROCOF and FN in the case of increasing the penetration of the wind power is performed to show the best controller structure and the controller combination structure that has the best index values. In all performed simulation tests, results for the interested variables without any control are recorded to show the effect of each controller on these variables.

\subsection{Condition 1 Simulation Results}

The importance of using control scheme for the frequency control problem under the proposed system configuration is completely reflected in Figure 12. If no control is applied, the ROCOF has high results in larger frequency excursion (in this case $\Delta f=2 \mathrm{~Hz}$ ) and lower FN (in this case TMF $=48 \mathrm{~Hz}$ ). These values cannot be accepted in regards to grid codes in different areas [26-28] where the normal frequency deviation ranges $\pm 0.02 \mathrm{~Hz}$ in Denmark, \pm 0.2 in Great Britain and $\pm 0.5 \mathrm{~Hz}$ in Egypt. Hence, proposing control scheme can play a vital role in alleviating this problem. Figure 12 shows the frequency response for four different control schemes. The different controllers enhance the frequency response with respect to the case of no control. Among these controllers, the inertia emulation control gives the best response and enjoys smoother dynamic characteristics. It reduces the TMF value remarkably which leads to lowering the frequency deviation and enhance the $\mathrm{FN}(\Delta f=1.75 \mathrm{~Hz}$ and TMF $=48.25 \mathrm{~Hz})$. Furthermore, the frequency response with this controller enjoys smoother dynamic characteristics. On the other hand, during the period of increasing the frequency to new steady state frequency deviation (the right side of Figure 12), the ROCOF of the inertia emulation control is lower than the other controllers. Table 2 compares the dynamics of each controller under the low wind speed condition.

Table 2. Dynamic comparison in low wind speed case.

\begin{tabular}{ccccc}
\hline & $\boldsymbol{\Delta} \boldsymbol{f}(\mathbf{H z})$ & TMF $\mathbf{( H z )}$ & ROCOF Decreasing & Settling Time- $\boldsymbol{t}_{\boldsymbol{s}}(\mathbf{s})$ \\
\hline Inertia Emulation Control & 1.75 & 48.25 & 0.02150 & 23.60 \\
Fast Power Reserve & 1.88 & 48.12 & 0.02085 & 25.63 \\
Emulation & 1.92 & 48.08 & 0.02168 & 23.67 \\
Droop Control & 1.93 & 48.07 & 0.02121 & 25.20 \\
De-Loading/Rotational & & & \\
Speed Control & &
\end{tabular}




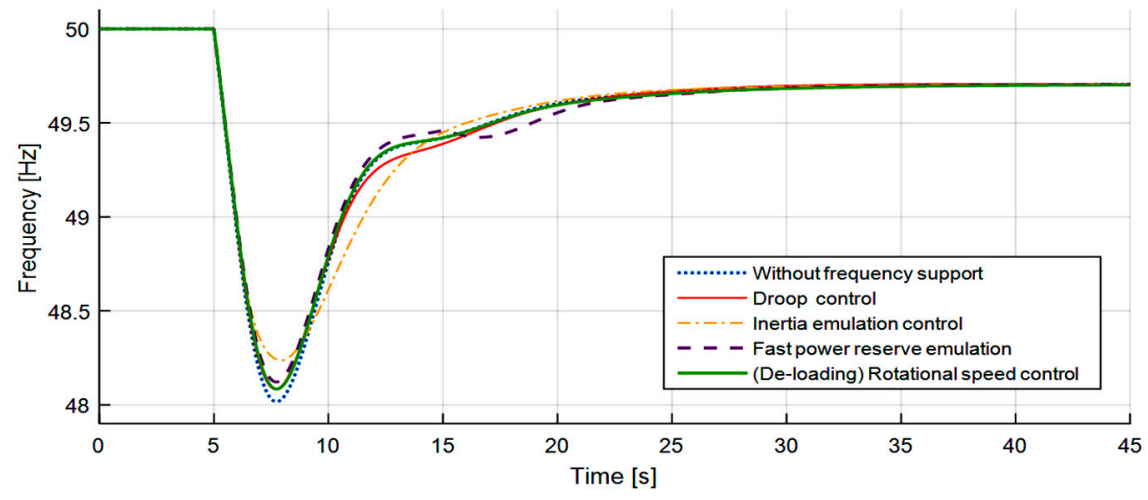

Figure 12. Frequency response for different controllers in low wind speed case after frequency disturbance.

In Table 2, it is noticed that all controllers used offer the same settling time and settle down to the same value of the steady state deviation.

Figure 13a,b shows the response of the wind turbine electrical power and rotor speed for different primary frequency controllers after the suggested unbalance event. It is noticed that the electrical power for fast power reserve emulation remains constant for $10 \mathrm{~s}$ with slight increase in the rotor speed compared to the speed before the frequency event. The trend for the electrical power for other controllers is approximately the same, where an instantaneous increase in the value of the electrical power occurs and is associated with decrease in rotor speed directly after the frequency event. This is followed by a decrease in the value of electrical power, which is associated with an increase in the rotor speed. The instantaneous maximum percentage increase in the wind turbine electrical power of inertia emulation, fast power reserve, droop, and de-loading control are $30 \%, 11 \%, 7.2 \%$ and $7 \%$, respectively, which enables the wind turbine to contribute in damping the grid frequency transient.

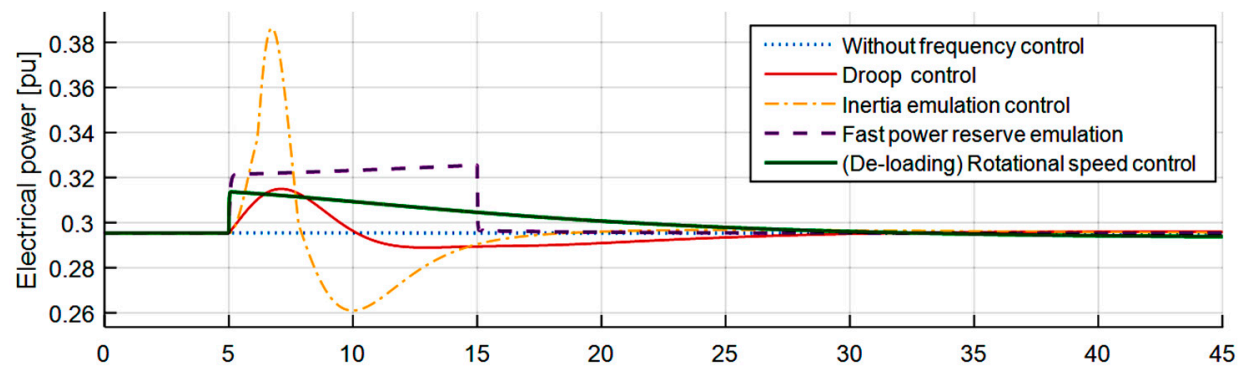

(a)

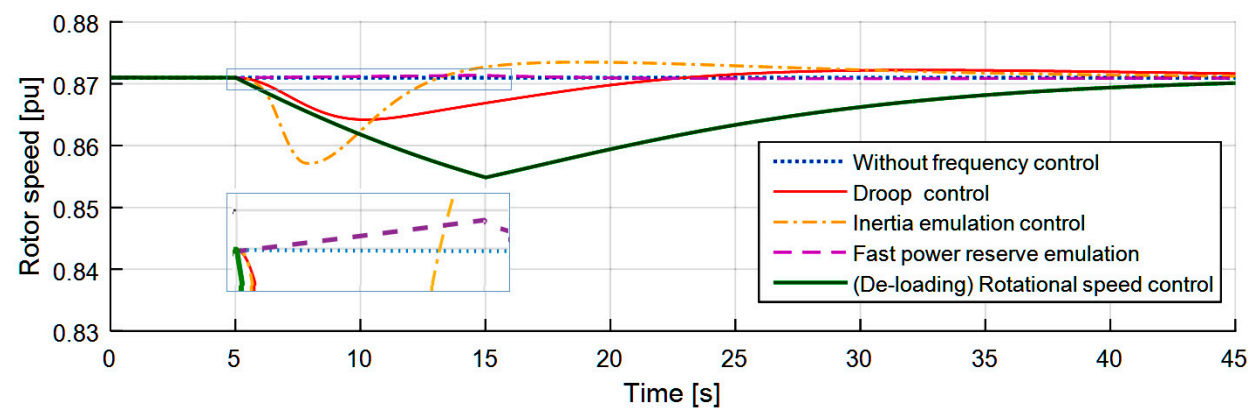

(b)

Figure 13. (a) Electrical power; and (b) rotor speed of VSWT in low wind speed case after frequency disturbance. 


\section{Remark 2}

1. Morren et al. [10] commented on the initial operating power of the turbine at the frequency disturbance event and the amount of available additional power in the turbine which is used to support the primary frequency response. In this paper, an investigation is performed to check the available additional power from the wind turbine in the case of higher wind speeds. This investigation is made for all four controllers. The wind speed range is chosen to be $7-11 \mathrm{~m} / \mathrm{s}$ with an increment of $0.5 \mathrm{~m} / \mathrm{s}$, where the rated speed is set to be $11.34 \mathrm{~m} / \mathrm{s}$. For sake of brevity, only the results for inertia emulation control case-as a best control candidate in low wind speed-are presented. Figure 14 shows that the amount of contributed power by the wind turbine is increased as the wind speed increases due to higher stored kinetic energy.

2. The conclusion that can be drawn here is that the wind turbine ability to provide instant additional power for primary frequency support is increasing as wind speed increases at low wind speed conditions.

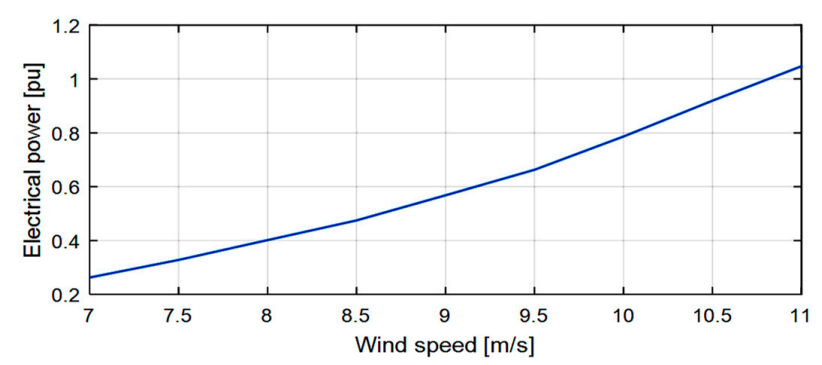

Figure 14. Contributed power of wind turbine vs. wind speed for only inertia emulation control case.

\subsection{Condition 2 Simulation Results}

In this simulation case, because the considered wind speed value is high, all the studied controllers (inertia emulation, droop, fast power reserve and de-loading) are accompanied with traditional pitch controller to regulate the pitch angle. The de-loading controller concept is achieved via applying a modified pitch control technique shown in Figure 11. Figure 15 reflects the importance of using control scheme for the frequency control problem under the proposed system configuration. It shows the frequency response for four different control schemes. It can be concluded that for both low and high wind speed, an additional control scheme rather than the traditional control (MPPT) needs to be implemented in the wind turbine converter to ensure good frequency indices and thus better frequency responses.

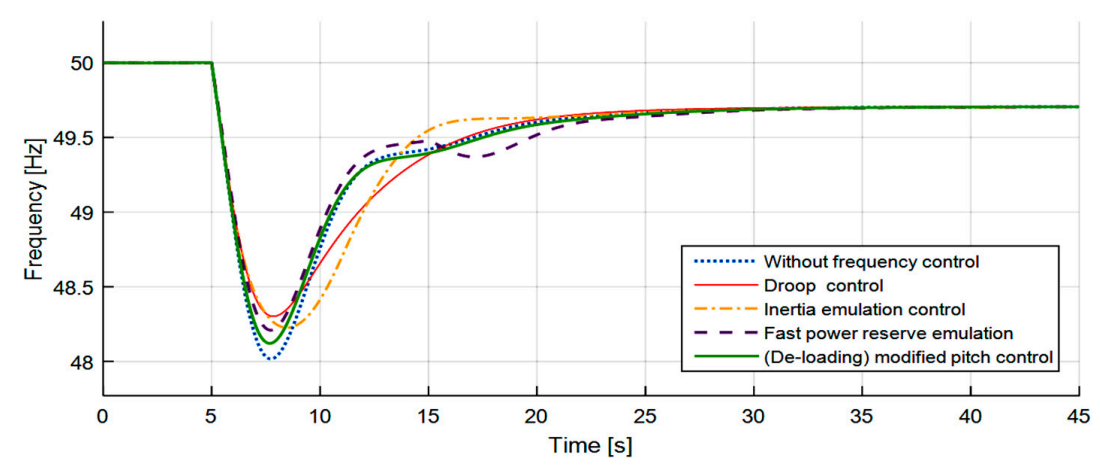

Figure 15. Frequency response for different controllers in high wind speed case after frequency disturbance.

In this case, the droop control outperforms all other proposed controllers in terms of FN and $\Delta f$ values. The ROCOF of this controller is also enhanced and the overall frequency response exhibits the 
smoothest dynamic characteristics. Moreover, the droop controller shows the fastest response. Table 3 compares the dynamics of each controller.

Table 3. Dynamic comparison in high wind speed case.

\begin{tabular}{ccccc}
\hline & $\Delta f \mathbf{H z})$ & TMF $\mathbf{~ H z )}$ & ROCOF Decreasing & Settling Time- $\boldsymbol{t}_{\boldsymbol{s}}(\mathbf{s})$ \\
\hline Droop Control & 1.72 & 48.28 & 0.02083 & 22.97 \\
Inertia Emulation & 1.74 & 48.26 & 0.02099 & 24.55 \\
$\quad$ Control & 1.79 & 48.21 & 0.02070 & 25.45 \\
$\begin{array}{c}\text { Fast Power Reserve } \\
\quad \text { Emulation }\end{array}$ & 1.88 & 48.12 & 0.02157 & 24.85 \\
$\begin{array}{c}\text { De-Loading/Modified } \\
\text { Pitch Control }\end{array}$ & & & & \\
\hline
\end{tabular}

Figure 16a-c shows the response of the wind turbine electrical power, rotor speed and pitch angle for different primary frequency controllers after the suggested unbalance event. It is noticed that the electrical power for fast power reserve emulation remains constant for $10 \mathrm{~s}$. The trend for the electrical power for other controllers is approximately the same, where an instantaneous increase in the value of the electrical power occurs and is associated with decrease in rotor speed directly after the frequency event. However, in this case, and due to the high value of the wind speed, the wind turbine rotor speed for the de-loading control (modified pitch control) is increased due to the reduction in the pitch angle value. The modified pitch angle controller shows a very high reduction rate for the pitch angle. This is followed by a decrease in the value of electrical power which is associated with an increase in the rotor speed except for the de-loading controller where the rotor speed starts to decrease. The instantaneous maximum percentage increase in the wind turbine electrical power of inertia emulation, fast power reserve, droop, and de-loading controllers are $11 \%, 5 \%, 8 \%$ and $2.5 \%$, respectively, which enables the wind turbine-in high wind speed—to contribute in damping the grid frequency transient.

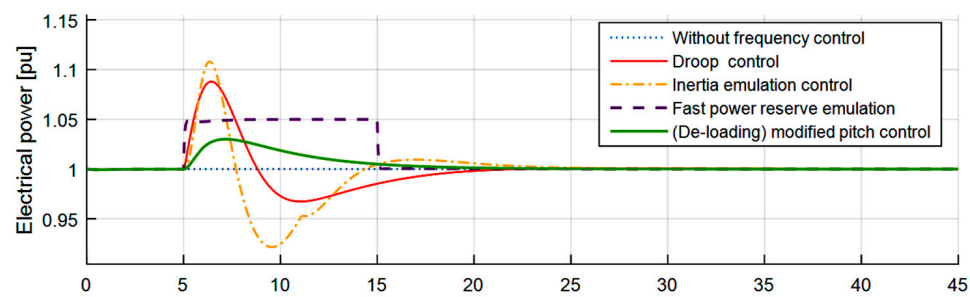

(a)

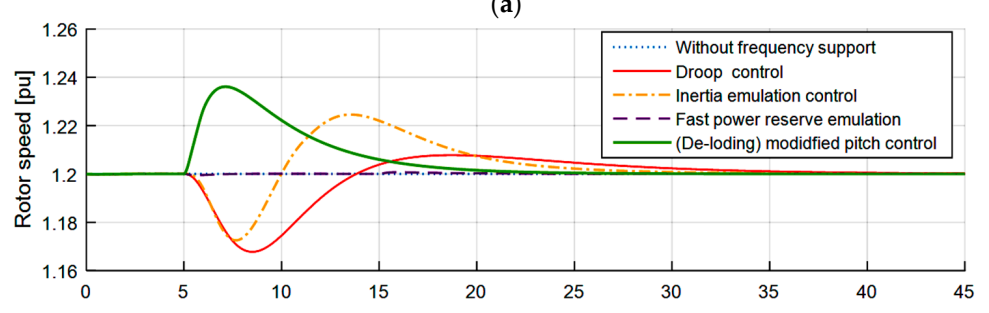

(b)

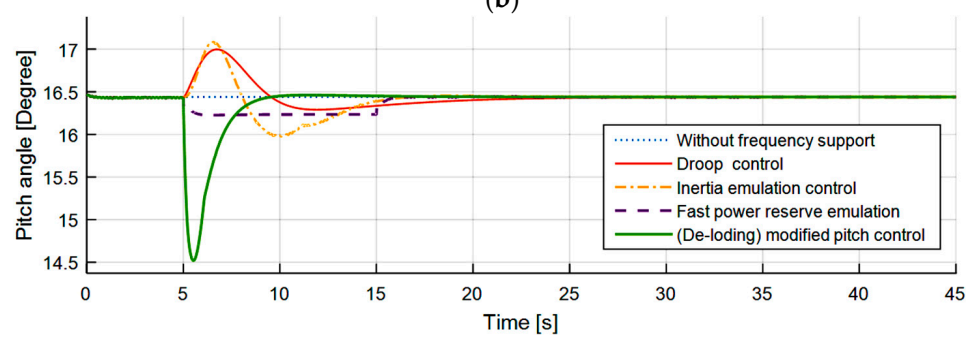

(c)

Figure 16. (a) Electrical power; (b) rotor speed; and (c) pitch angle of VSWT in high wind speed case after frequency disturbance. 


\section{Remark 3}

1. All controller structures provide higher power reserve margins under low wind speed conditions compared to the case of high wind speed conditions.

2. The dynamics of pitch angle response in the case of de-loading controller is much higher than the corresponding dynamics for the other controllers. Hence, the pitch angle mechanism in the de-loading controller needs to be highly responsive and more efficient to achieve these dynamics, which will affect the total cost of the wind turbine.

\section{Combination Controllers' Results}

In this section, to enhance the frequency response during the time of frequency drop more than the results in the previous sections, novel combination controllers following the combination matrix (Table 1) are adopted. The controllers suggested in this section are mainly based on merging the inertial response control and the de-loading control concepts. Same wind speed conditions and same system variables are studied. The inertial response controllers chosen here are inertia emulation and fast power reserve emulation. The de-loading controllers are the rotational speed control in the low wind speed and the modified pitch control in high wind speed. The case of no control is also presented for the sake of comparison.

\subsection{Low Wind Speed}

As can be inferred from Figure 17, both combined controllers improve the frequency response more than the case where no control is applied. In general, the suggested combinations enhance the TMF values (FN values) and the settling time. For example, TMF for the inertia emulation controller alone is $48.25 \mathrm{~Hz}$, while, in the case of combination with rotational speed control, is $48.28 \mathrm{~Hz}$. The settling time is more than $15 \mathrm{~s}$ for the inertia emulation controller alone, while, in the case of combination with rotational speed control, is less than $15 \mathrm{~s}$. In these wind speed conditions, the inertia emulation control is superior to fast power reserve control when combined with rotational speed control.

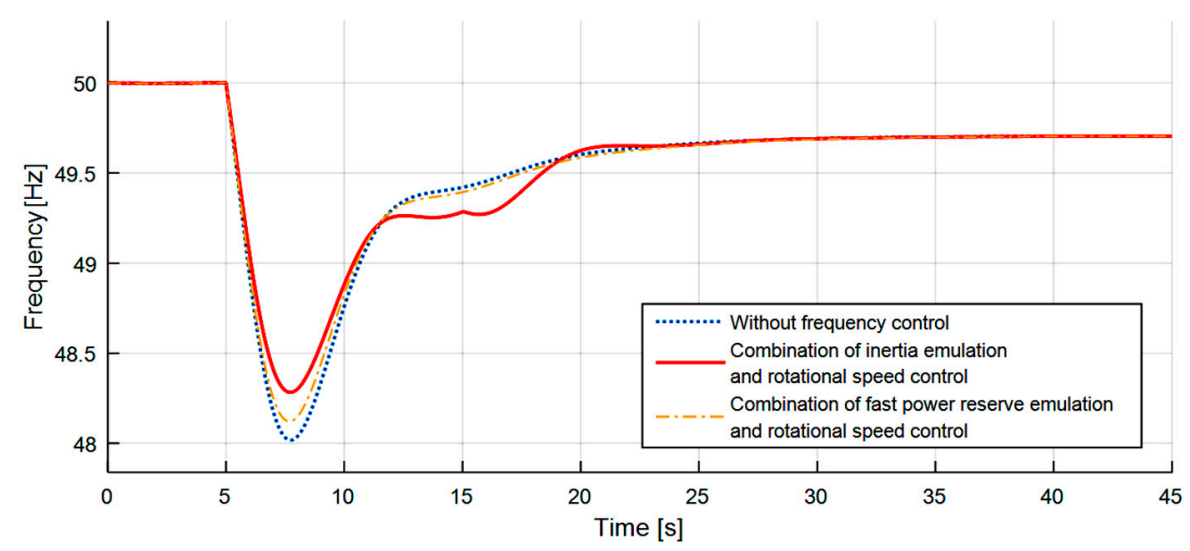

Figure 17. Frequency response for different controllers in Low wind speed case after frequency disturbance.

Figure 18a,b shows the response of electrical power and rotor speed for both combined controllers. The electrical power given by the wind turbine before and after the frequency event has no change in the case of no control. The instantaneous electrical power given by the wind turbine directly after the frequency event in the case of inertia emulation is higher than its corresponding value in the case of fast power reserve emulation. Despite the combination, the results here are in line with the results obtained with low speed and no combination. The instantaneous maximum percentage increase in the 
electrical power given by the wind turbine for inertia emulation and fast power reserve combinations with rotational speed control are approximately $7 \%$ and $2.5 \%$, respectively.

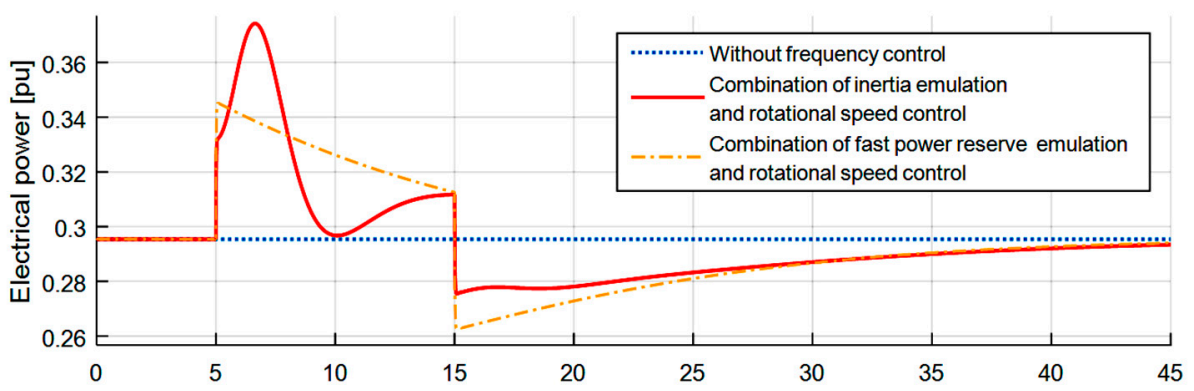

(a)

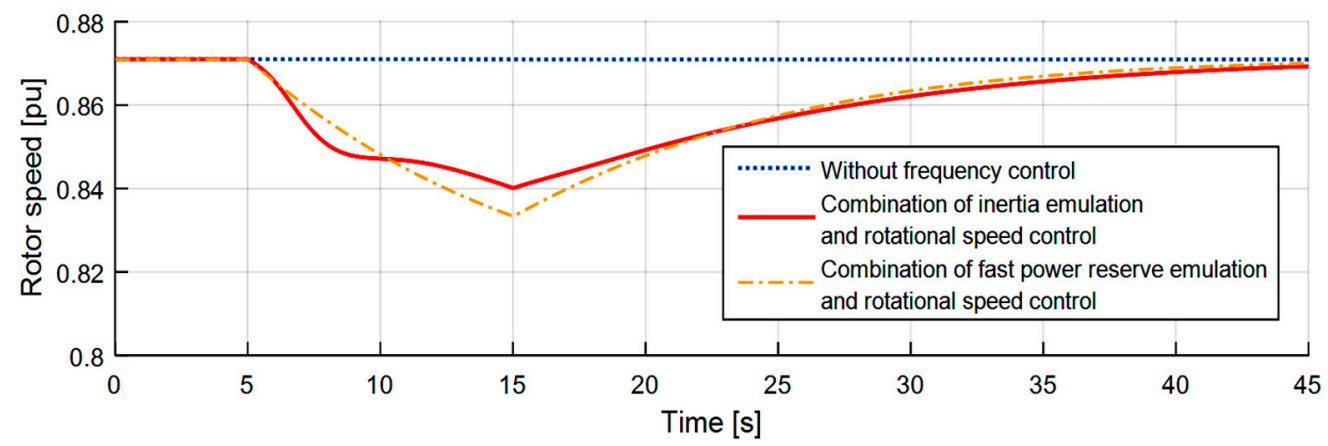

(b)

Figure 18. (a) Electrical power; and (b) rotor speed of VSWT in low wind speed case after frequency disturbance.

\subsection{High Wind Speed}

In this wind speed condition, the combined controllers show better frequency responses than the case with no control (see Figure 19). The inertia emulation combination case is the best and yields the best frequency response under the imbalance frequency event. The response of this controller reflects very low TMF and ROCOF values when compared with the same values of the same controller (combined with rotational speed control) but in low wind speed condition or even if compared with the results obtained in the case of inertia emulation controller alone in low wind speed.

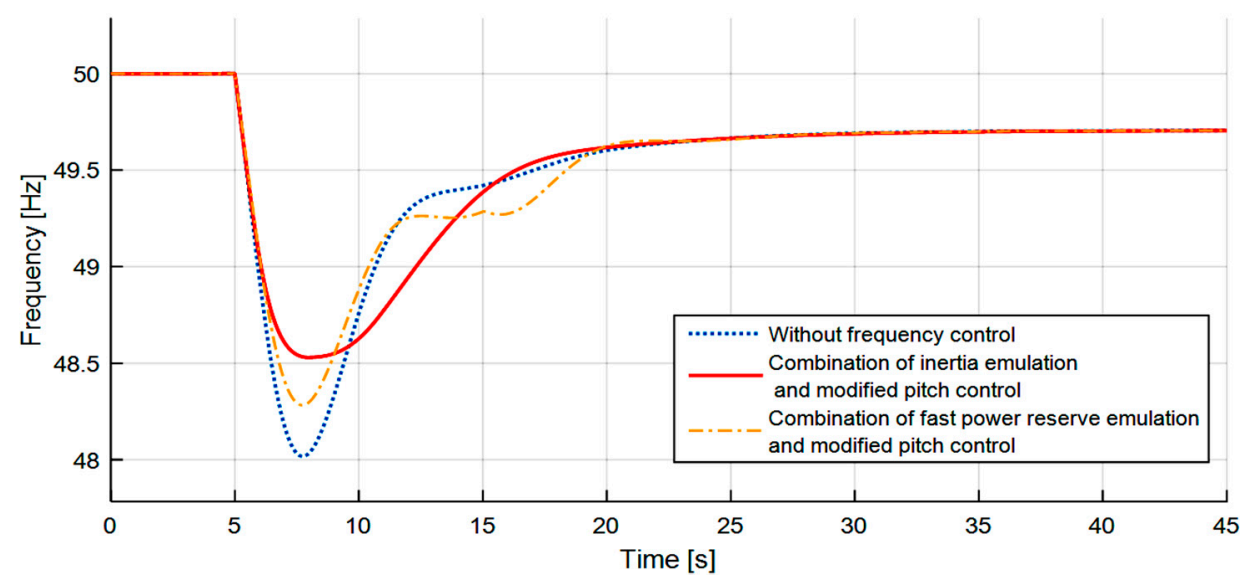

Figure 19. Frequency response for different controllers in high wind speed case after frequency disturbance.

This controller combination enables the wind turbine to provide the highest electrical power and perform the lowest reduction in pitch angle when compared to the fast power reserve emulation 
controller case, as shown in Figure 20a-c. The maximum percentage increase in the wind turbine electrical power for inertia emulation and fast power reserve combinations with modified pitch control are approximately $15 \%$ and $5 \%$, respectively, which enables the wind turbine-in high wind speed-to contribute in damping the grid frequency transient.

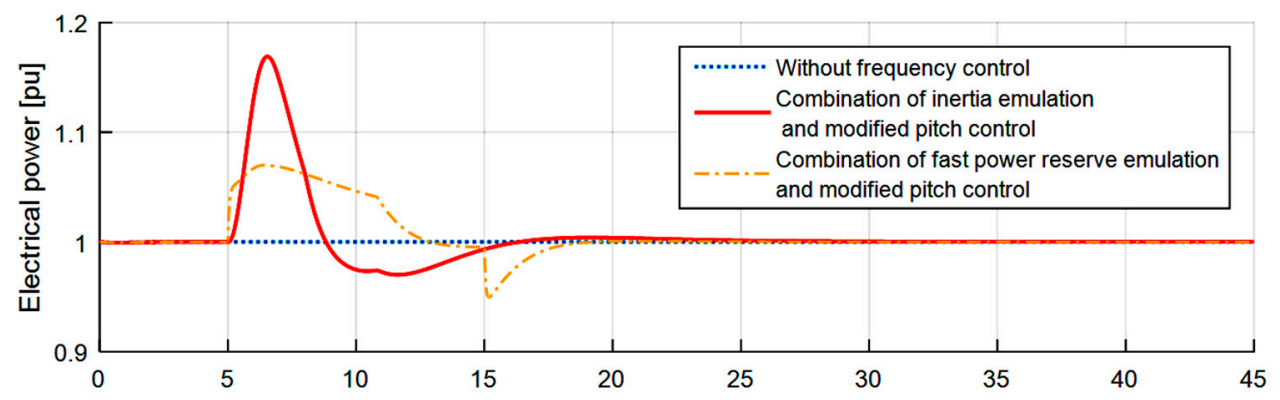

(a)

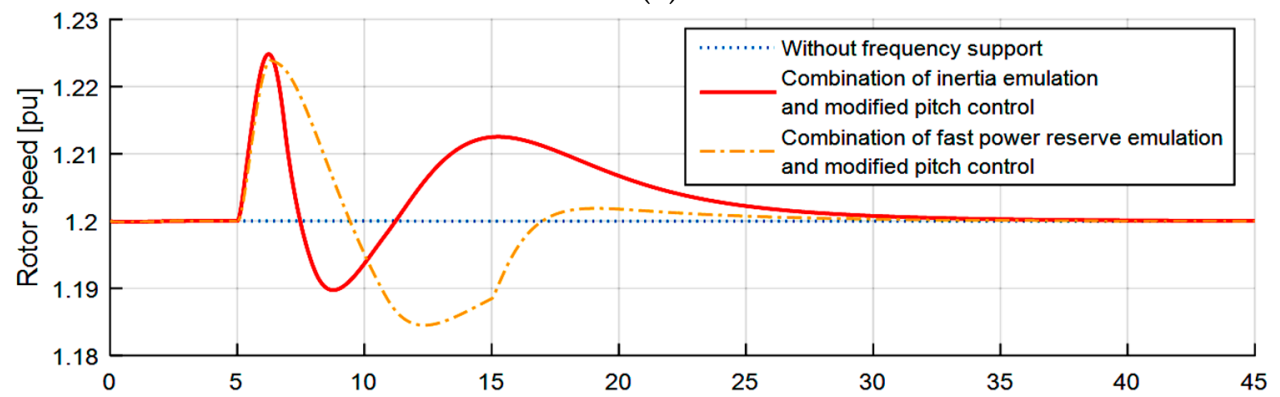

(b)

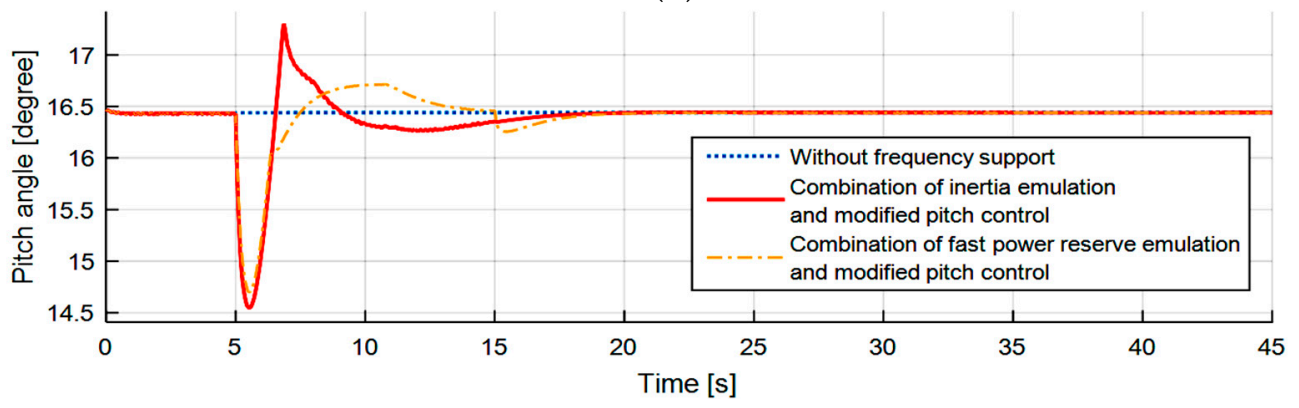

(c)

Figure 20. (a) Electrical power; (b) rotor speed; and (c) pitch angle of VSWT in high wind speed case after frequency disturbance.

\section{Effect of High Wind Power Penetration}

The impact of increasing the wind penetration level in the proposed sample of hydro dominated power system is studied in low and high wind speed. System security indices such as ROCOF and FN are calculated from the simulation. All proposed controllers in the previous section are checked against a gradual variation of the wind penetration level that ranges $0-40 \%$.

\subsection{Low Wind Speed}

Figure 21 shows the ROCOF and FN with increasing wind power penetration level in low wind speed case. Figure 21a reflects the following points:

- As the penetration level of wind power increase, the ROCOF also increases, whether using or not using control system and independent of the used controller type. 
- At very low penetration levels (0-10\%), the combined control techniques offer a good method-to reduce the ROCOF values-and can be considered superior to the four proposed separate control techniques.

- At very high penetration levels (35-40\%), there is no great difference in the FOCOF values with different controllers. This means that, at this high level of penetration, any controller either in combination or alone can be used to primarily capture the frequency.

- At the penetration level 0-20\%, the fast power reserve emulation combined with rotational speed control offer the best frequency control alternative to reduce the ROCOF values.

- From $20 \%$ to $40 \%$ penetration level, both combination cases yield same ROCOF values. However, the combination of inertia emulation with rotational speed control is the best when the FN is considered.

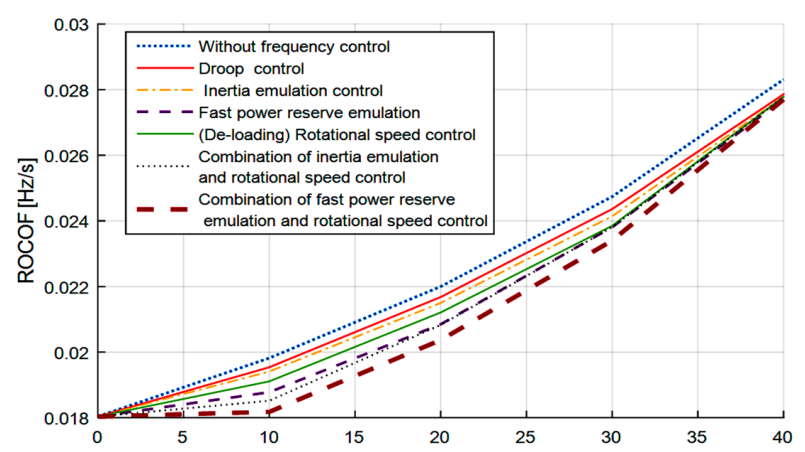

(a)

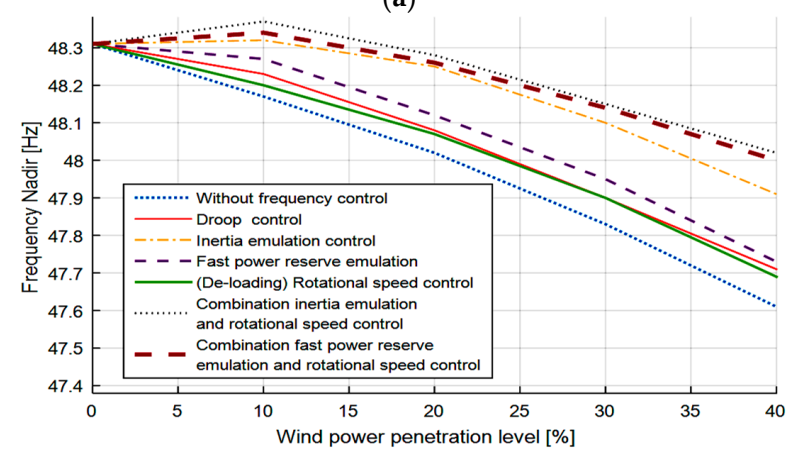

(b)

Figure 21. (a) ROCOF; and (b) FN vs. wind power penetration level in low wind speed case.

Figure $21 \mathrm{~b}$ reflects the following points:

- The (FN) values starts to decrease as the penetration level of wind power starts to increase if there is no frequency control action.

- At very low penetration levels (0-10\%), the combined control techniques as well as the inertia emulation control offer superior methods to increase the FN values. The three other proposed separate control techniques cannot increase the FN in this range of penetration level.

- At penetration level above $10 \%$, the behavior of the FN starts to alternatively decrease with all suggested separate and combined controllers.

- At very high penetration levels (30-40\%), the combined control techniques present superior methods over the other controllers to increase the FN values with no big difference in the FN values for these combined controllers.

- At the penetration level 0-40\%, the inertia emulation control outperforms the other separate controllers in increasing the FN values, whether it is used separately or in a combined manner with rotational speed control. 


\subsection{High Wind Speed}

Figure 22 shows the ROCOF and FN with increasing wind power penetration level at high wind speed. Figure 22a reflects the following points:

- As the penetration level of wind power increase, the ROCOF also increases, whether using or not using control system and independent of the used controller type.

- At very low penetration levels $(0-10 \%)$, the fast power reserve emulation combined with modified pitch control technique and the droop control represent the best methods to reduce the ROCOF values.

- From $10 \%$ to $35 \%$ penetration levels, the fast power reserve control either in combination or alone represents the best alternative to reduce the ROCOF values.

- At very high penetration levels (35-40\%), there is no big difference in the FOCOF values for different controllers. This means that, at this high level of penetration, any controller either in combination or alone can be used to primarily capture the frequency.

Figure 22b reflects the following points:

- As the penetration level of wind power increases, the FN also increases for all proposed controllers except the combination of inertia emulation and modified pitch, where the FN decreases for the penetration level from $0 \%$ to $20 \%$ and increase after that until $40 \%$.

- At the penetration level $10-40 \%$, the inertia emulation control combined with modified pitch control offers the best frequency control alternative to reduce the FN values.

- At the penetration level $10-40 \%$, the droop control seems to be the best separate controller, yielding low values of FN.

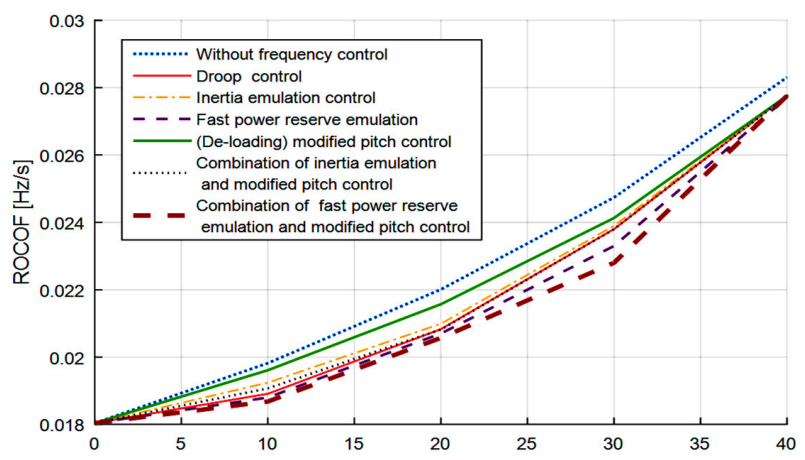

(a)

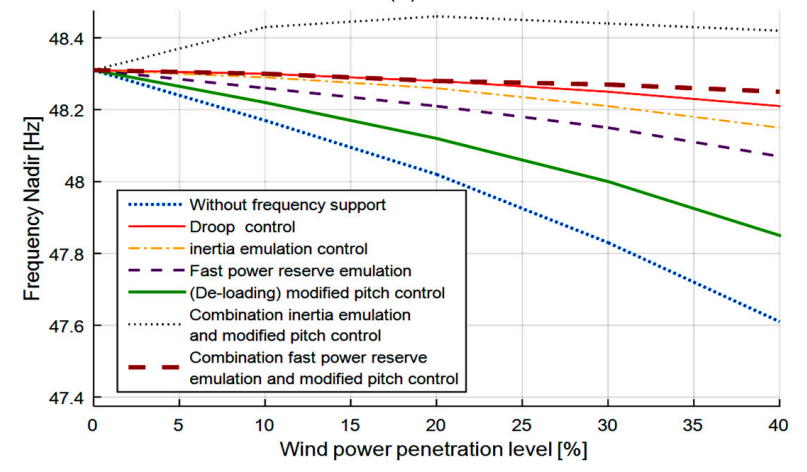

(b)

Figure 22. (a) ROCOF; and (b) FN vs. wind power penetration level in high wind speed case.

\section{Remark 4}

The work in this paper differs from [22-24] in the following points: 
1. More controller schemes are studied.

2. The work in this paper considers a wider spectrum of wind speeds.

3. A new combined control scheme is proposed.

\section{Conclusions}

This paper compares the control performance of four primary frequency controllers for VSWT to support the system frequency in the full range of wind speed. In particular, inertia emulation control, fast power reserve control, droop control and de-loading control are studied, both separate and combined. The simulation results show that theses controllers can successfully improve the frequency response in the case of generation/consumption power imbalance. The simulation also reflects the following points:

- The best control performance achieved in low wind speed in terms of ROCOF, FN and $\Delta f$ is the inertia emulation.

- This controller enables the wind turbine to provide the maximum active power in the case of frequency event, hence offers best damping for grid transient.

- The best control performance achieved in high wind speed in terms of ROCOF, FN and $\Delta f$ is the droop control. This controller presents the highest response speed.

- The results obtained in low wind speed for the inertia emulation controller can be more enhanced in the case of combination with rotational speed controller.

- The inertia emulation combination with the modified pitch control in high wind speed exhibits the best control performance ever in terms of ROCOF, FN and $\Delta f$, in different cases of low and high wind speed. This combined controller represents shorter settling time (i.e., faster response).

Finally, the paper introduces full comparison between the studied controllers, both separate and combined, in terms of ROCOF and FN subjected to increase in the wind power penetration level. This comparison reveals that the combination solution offers better ROCOF and FN values in both low and high wind speed conditions.

Author Contributions: Abdulhameed S. Alsharafi carried out the simulations and collaborated in the design of the control strategies. Ahmad H. Besheer analyzed the results and formulated the discussions in the manuscript. Hassan M. Emara collaborated in the design of the control strategies and reviewed the paper.

Conflicts of Interest: The authors declare no conflict of interest.

\section{References}

1. Borlase, S. (Ed.) Smart Grids: Infrastructure, Technology, and Solutions; CRC Press: Boca Raton, FL, USA, 2017.

2. Global Wind Report. 2016. Available online: http://www.gwec.net/ (accessed on 10 May 2017).

3. Wang, Y.; Meng, J.; Zhang, X.; Xu, L. Control of PMSG-based wind turbines for system inertial response and power oscillation damping. IEEE Trans. Sustain. Energy 2015, 6, 565-574. [CrossRef]

4. Bevrani, H. Robust Power System Frequency Control; Springer: New York, NY, USA, 2014.

5. Pourbeik, P.; Sanchez-Gasca, J.J.; Senthil, J.; Weber, J.D.; Zadehkhost, P.S.; Kazachkov, Y.; Ellis, A. Generic Dynamic Models for Modeling Wind Power Plants and Other Renewable Technologies in Large-Scale Power System Studies. IEEE Trans. Energy Convers. 2017, 32, 1108-1116. [CrossRef]

6. Bossanyi, E. Generic grid frequency response capability for wind power plant. In Proceedings of the EWEA Annual Conference, Paris, France, 17-20 November 2015.

7. Poolla, B.K.; Bolognani, S.; Dörfler, F. Optimal placement of virtual inertia in power grids. IEEE Trans. Autom. Control 2017, 62, 6209-6220. [CrossRef]

8. Dreidy, M.; Mokhlis, H.; Mekhilef, S. Inertia response and frequency control techniques for renewable energy sources: A review. Renew. Sustain. Energy Rev. 2017, 69, 144-155. [CrossRef]

9. Sun, Y.Z.; Zhang, Z.S.; Li, G.J.; Lin, J. Review on frequency control of power systems with wind power penetration. In Proceedings of the International Conference on Power System Technology, Hangzhou, China, 24-28 October 2010; pp. 1-8. 
10. Morren, J.; De Haan, S.W.H.; Kling, W.L.; Ferreira, J.A. Wind turbine emulating inertia and supporting primary frequency control. IEEE Trans. Power Syst. 2006, 21, 433-434. [CrossRef]

11. Morren, J.; Pierik, J.; De Haan, S.W.H. Inertial response of variable speed wind turbines. Electr. Power Syst. Res. 2006, 76, 980-987. [CrossRef]

12. Zeni, L.; Rudolph, A.; Margaris, I.; Münster-Swendsen, J.; Hansen, A.D.; Sørensen, P. Virtual inertia for variable speed wind turbines. Wind Energy 2012, 8, 1225-1239. [CrossRef]

13. Gonzalez-Longatt, F.M. Effects of the synthetic inertia from wind power on the total system inertia: Simulation study. In Proceedings of the 2nd International Symposium on Environment-Friendly Energies and Applications, Newcastle upon Tyne, UK, 25-27 June 2012; pp. 389-395.

14. Gonzalez-Longatt, F.M. Impact of emulated inertia from wind power on under-frequency protection schemes of future power systems. J. Mod. Power Syst. Clean Energy 2016, 4, 211-218. [CrossRef]

15. Gonzalez-Longatt, F.M.; Bonfiglio, A.; Procopio, R.; Verduci, B. Evaluation of inertial response controllers for full-rated power converter wind turbine (Type 4). In Proceedings of the IEEE Power and Energy Society General Meeting, Boston, MA, USA, 17-21 July 2016.

16. Yingcheng, X.; Nengling, T. Review of contribution to frequency control through variable speed wind turbine. Renew. Energy 2011, 36, 1671-1677. [CrossRef]

17. Motamed, B.; Chen, P.; Persson, M. Comparison of primary frequency support methods for wind turbines. In Proceedings of the IEEE Grenoble PowerTech, Grenoble, France, 16-20 June 2013; pp. 1-5.

18. Gonzalez-Longatt, F.M. Impact of Synthetic Inertia from Wind Power on the Protection/Control Schemes of Future Power Systems: Simulation Study. Presented at the DPSP 2012_Protecting the Smart Grid, the 11th International Conference on Developments in Power System Protection, Birmingham, UK, 23-26 April 2012.

19. Gonzalez-Longatt, F. Frequency Control and Inertial Response Schemes for the Future Power Networks. In Large Scale Renewable Power Generation; Hossain, J., Mahmud, A., Eds.; Springer: Singapore, 2014; pp. 193-231.

20. Kundur, P. Power System Stability and Control; McGrawHill: New York, NY, USA, 1993.

21. Miller, N.W.; Sanchez-Gasca, J.J.; Price, W.W.; Delmerico, R.W. Dynamic modeling of 1.5 and 3.6 MW wind turbine-generators for stability simulations. In Proceedings of the IEEE Power Engineering Society General Meeting, Toronto, ON, Canada, 13-17 July 2003; pp. 1977-1983.

22. Teninge, A.; Jecu, C.; Roye, D.; Bacha, S.; Duval, J.; Belhomme, R. Contribution to frequency control through wind turbine inertial energy storage. IET Renew. Power Gener. 2009, 3, 358-370. [CrossRef]

23. Ullah, N.R.; Thiringer, T.; Karlsson, D. Temporary Primary Frequency Control Support by Variable Speed Wind Turbine- Potential and Application. IEEE Trans. Power Syst. 2008, 23, 601-612. [CrossRef]

24. Muller, S.; Deicke, M.; De Doncker, R.W. Doubly fed induction generator systems for wind turbines. Ind. Appl. Mag. 2002, 8, 26-33. [CrossRef]

25. De Almeida, R.G.; Lopes, J.P. Participation of doubly fed induction wind generators in system frequency regulation. IEEE Trans. Power Syst. 2007, 22, 944-950. [CrossRef]

26. Complete Grid Code. Available online: https://www.nationalgrid.com/uk/electricity/codes/grid-code? code-documents (accessed on 21 March 2017).

27. National Electricity Rules Version 106. Australian Energy Market Commission (AEMC). Available online: http:/ / www.aemc.gov.au (accessed on 27 February 2018).

28. Wind Farm Grid Connection Code in Addition to the Egyptian Transmission Grid Code. Available online: http:/ / www.egyptera.org (accessed on 15 September 2017).

(C) 2018 by the authors. Licensee MDPI, Basel, Switzerland. This article is an open access article distributed under the terms and conditions of the Creative Commons Attribution (CC BY) license (http://creativecommons.org/licenses/by/4.0/). 